\title{
The relation between serum uric acid levels and diabetic peripheral neuropathy in type 2 diabetes in Guilan, north of Iran
}

\author{
Haniye Sadat Fayazi ${ }^{1}$, Maryam Yaseri ${ }^{*}$, Seyyede Sahere Mortazavi ${ }^{1}$, Zahra Sharifhassan ${ }^{2}$ and Ali-Sina Assadinia ${ }^{2}$
}

\begin{abstract}
Background: Diabetic peripheral neuropathy (DPN) is one of the most common chronic microvascular complications in type 2 diabetes mellitus (T2DM). Hence, the present study aimed to investigate the association between Serum Uric Acid (SUA) levels and diabetic peripheral polyneuropathy in patients with type 2 diabetes.

Methods: We performed this case-control study during 2019-2020 on individuals with diabetes referring to the Razi clinic of Rasht, in the north of Iran. Polyneuropathy in patients was assessed based on the Neuropathy Disability Score (NDS), Diabetic neuropathy symptom score (DNS) scoring system, and electromyography (EMG)/nerve conduction velocity (NCV). The inclusion criterion for the control group was normal EMG/NCV. Then, the patients were assessed for SUA level and also laboratory results.
\end{abstract}

Results: In total, 230 patients with type 2 diabetes were examined. The mean SUA level in the DPN group was significantly higher compared to the control group ( $6.72 \pm 1.75 \mathrm{vs} .4 .57 \pm 1.49 \mathrm{mg} / \mathrm{dL}$ ). With increasing the SUA, the odds of developing neuropathy increased by 2.2 times $(\mathrm{OR}=2.2)$. The risk factors for diabetic polyneuropathy included gender (male) $(O R=0.347)$, SBP $(O R=1.1)$, retinopathy $(O R=3.29)$, and microalbuminuria $(O R=4.44)$. The chance of developing polyneuropathy in patients with retinopathy was 3.3 times higher than in the control group, it was 4.4 times in microalbuminuria patients.

Conclusion: Elevated SUA level increased the chance of developing peripheral polyneuropathy in a person with type 2 diabetes. SUA levels higher than $5.25 \mathrm{mg} / \mathrm{dL}$ expose a person with type 2 diabetes to developing peripheral polyneuropathy.

Keywords: Type 2 diabetes, Diabetic polyneuropathy, Uric acid, Cardiovascular disease

\section{Background}

Type 2 diabetes mellitus (T2DM) is associated with longterm complications resulting in cardiovascular diseases, renal failure, and nephropathy $[1,2]$. It has increased health problems and become a worldwide concern [3, 4]. Type 2 DM involves $90-95 \%$ of diabetics and is more prevalent among the elderly [5, 6]. Diabetic Peripheral

\footnotetext{
*Correspondence: maryam.yaseri21@yahoo.com

${ }^{1}$ Department of Internal Medicine, School of Medicine, Razi Hospital,

Guilan University of Medical Sciences, Rasht, Iran

Full list of author information is available at the end of the article
}

Neuropathy (DPN) is one of the most common chronic microvascular complications in progressing of T2DM to diabetic foot ulcer [6]. It frequently leads to amputation and/or disability and death. DPN accounts for $30-50 \%$ of patients with diabetic leg and foot ulcers [7]. The main related factors included age $>40$ years, obesity, and hypertension [8-10]. However, its prevalence and the risk factors on a global scale remain unclear especially in the low- and middle-income countries. Previous research revealed that hyperuricemia with hyperglycemia, insulin resistance, dyslipidemia, and metabolic syndrome, all

(c) The Author(s) 2022. Open Access This article is licensed under a Creative Commons Attribution 4.0 International License, which permits use, sharing, adaptation, distribution and reproduction in any medium or format, as long as you give appropriate credit to the original author(s) and the source, provide a link to the Creative Commons licence, and indicate if changes were made. The images or other third party material in this article are included in the article's Creative Commons licence, unless indicated otherwise in a credit line to the material. If material is not included in the article's Creative Commons licence and your intended use is not permitted by statutory regulation or exceeds the permitted use, you will need to obtain permission directly from the copyright holder. To view a copy of this licence, visit http://creativecommons.org/licenses/by/4.0/. The Creative Commons Public Domain Dedication waiver (http://creativeco mmons.org/publicdomain/zero/1.0/) applies to the data made available in this article, unless otherwise stated in a credit line to the data. 
are involved in the development of diabetic neuropathy [11-13].

According to the reports in 2020, serum uric acid (SUA) level $\geq 7.3 \mathrm{mg} / \mathrm{dL}$ was found to be associated with an increase in peripheral neuropathy [14]. The high SUA level was related to the incidence of macro and microvascular complications in patients with DM. An elevated level of SUA in T2DM was associated with metabolic syndrome and insulin resistance [15], as well as with a higher risk of developing diabetic polyneuropathy [16]. Previous research identified SUA as a sign of oxidative stress from hyperuricemia, which can cause insulin resistance, diabetes, and cardiovascular disease [17]. However, SUA -lowering therapy has a positive effect on reducing the incidence of T2DM and insulin resistance [18].

The presence of DPN affects the quality of life and increases death from cardiovascular disease. Unfortunately, there is no certain therapy definitively eliminating the symptoms of diabetic neuropathy. Therefore, identifying the relationship between diabetic polyneuropathy and its associated risk factors is essential to determine appropriate treatment and provide prevention and screening measurements. Acceding to the previous studies, there is a significant relationship between SUA levels and diabetic peripheral polyneuropathy. However, there is still no agreement among them, and further studies are recommended in this area. This study aimed to investigate the relationship between SUA levels and diabetic peripheral polyneuropathy in patients with type 2 diabetes referring to RAZI Clinic in Rasht during 2019-2020.

\section{Material \& method}

\section{Patients and design}

In this case-control study, individuals with diabetes referring to Razi Clinic in Rasht, the north of Iran, during 2019-2020 were studied. The patients were included by the Consecutive sampling method and based on diabetic peripheral polyneuropathy. They were evaluated in two groups of patients with and without diabetic peripheral polyneuropathy (control group). The two groups were matched in terms of age, sex, BMI, and disease duration of diabetes.

\section{Inclusion and exclusion criteria}

All individuals with diabetes were included in this study. The exclusion criteria included the age of less than 18 or over 75 years; underlying disease of gout, peripheral arterial disease, chronic kidney disease (creatinine $>2 \mathrm{mg}$ / $\mathrm{dL}$ or eGFR $<30 \mathrm{~min}$ ), chronic or acute infections, and blood disorders; taking drugs affecting the serum level of SUA such as diuretics, cyclosporine, allopurinol, estrogen, and cytotoxic drugs; and the presence of factors resulting in neuropathy such as vitamin B12 deficiency, alcohol abuse, cancer, and peripheral nerve damage.

\section{Assessment tools and measurements}

Polyneuropathy in patients was examined by the Neuropathy Disability Score (NDS), Diabetic neuropathy symptom score (DNS) scoring system, and electromyography (EMG)/nerve conduction velocity (NCV). The person with type 2 diabetes was initially evaluated according to the DNS scoring system through four sign points including unsteadiness in walking, numbness, burning/aching pain or tenderness in the lower limbs, and prickling sensation. Patients who did not score were considered as the control group (without peripheral polyneuropathy). The patients with at least one score were evaluated for the NDS scoring system based on the signs of neuropathy in the ankle reflex (Achilles), the pinprick, temperature sensation at both sides of the great toes, and vibration sensation (128- $\mathrm{Hz}$ tuning fork). The patients with an NDS score $\geq 6$, were diagnosed with diabetic peripheral polyneuropathy. The patients with a score $<6$ and with at least one of the four points of DNS, were subjected to EMG / NCV. By the abnormal EMG / NCV, the patients were diagnosed with DPN; otherwise included in the control group. In this study, demographic information was also recorded including age, gender, smoking status (one per day for at least two years), history of kidney disease or hypertension. Information on the SUA levels was evaluated along with LDL, HDL, Total Cholesterol, Triglyceride, HB1AC, and serum creatinine in two groups of patients. SUA status was considered based on the study of Xiaopu Lin et al. [19] in four categories ( $>5$, $5.1-7,7.1-9,>9)$. Microalbuminuria was examined based on the latest urine random test, which confirmed the ratio of albumin to urinary creatinine between $30 \mathrm{mg} / \mathrm{g}$ microalbuminuria.

\section{Statistical analysis}

An Independent T-test was used to analyze the data and compare the two groups. A chi-squared test was utilized to compare the frequency distribution of SUA levels in the two groups. Pearson and Spearman correlation coefficient was used to determine the correlation of SUA level with the studied quantitative variables (systolic pressure, diastolic pressure, lipid profile, and serum creatinine). Ultimately, the logistic regression model was utilized to determine the relationship between SUA levels and diabetic polyneuropathy after adjusting for the effects of individual and social interfering variables. The significance level of tests in this study was considered as $P<0.05$. All statistical analyses were performed using SPSS 16 (IBM Corp., USA). Statistical significance level was considered as a $P$-value of $<0.05$. 
Also, CBC test was measured at Razi Hospital by (Sysmex XK 21-N, Germany) and creatinine and albumin levels were measured by (HITACHI autoanalyzer 717, Tokyo, Japan).

\section{Results}

In the present study, 230 people with type 2 diabetes were studied in two groups of patients with and without peripheral diabetic polyneuropathy. The mean age of patients was $57.4 \pm 8.1$ years and ranged from 36 to 74 years. Of the total patients, $69.6 \%$ were females. The mean BMI was $28.1 \pm 4.6$. The patients with overweight were $38.7 \%$, obese $22.6 \%$, and very obese were $10 \%$. There was no significant difference between the two groups regarding age $(P=0.669)$, gender $(P=0.667)$, and
BMI $(P=0.427)$. The diabetes duration in patients with peripheral diabetic polyneuropathy was $12.9 \pm 7.9$ years and it was $10.3 \pm 6.13$ years in those without $(p=0.004)$. Other patient information in the two groups is presented in Table 1.

In total, $18.7 \%$ of the patients was a smoker and the frequency of smoking was not significantly different between the two groups. Diabetic retinopathy was found in $39.6 \%$ of the patients. In the DPN group, it was seen in $57.4 \%$, which was approximately 5.2 times higher than the control group $(21.7 \%)(P<0.001)$. Microalbuminuria was observed in $46.1 \%$ of patients. In the DPN group, it was observed in $68.7 \%$, which was almost 3 times higher than the control group $(23.5 \%)(P<0.001)$. Systolic blood pressure $(P=0.05)$, FBS $(P=0.001)$, HbA1c $(P<0.001)$,

Table 1 Comparing patients 'characteristics between DPN and control group

\begin{tabular}{|c|c|c|c|c|c|c|c|c|}
\hline \multirow[t]{2}{*}{ Variable } & \multirow[t]{2}{*}{ level } & \multicolumn{2}{|l|}{ DPN } & \multicolumn{2}{|l|}{ Control } & \multicolumn{2}{|l|}{ Total } & \multirow[t]{2}{*}{$P$-value } \\
\hline & & $\mathrm{n}$ & $\%$ & $\mathrm{n}$ & $\%$ & $\mathbf{n}$ & $\%$ & \\
\hline \multirow[t]{3}{*}{ Age (y) } & $<50$ & 20 & 17.4 & 25 & 21.7 & 45 & 19.6 & 0.669 \\
\hline & $51-60$ & 53 & 46.1 & 48 & 41.7 & 101 & 43.9 & \\
\hline & $>60$ & 42 & 36.5 & 42 & 36.5 & 84 & 36.5 & \\
\hline \multirow[t]{2}{*}{ Gender } & Female & 78 & 67.8 & 82 & 71.3 & 160 & 69.6 & 0.667 \\
\hline & Male & 37 & 32.2 & 33 & 28.7 & 70 & 30.4 & \\
\hline \multirow[t]{5}{*}{ BMl } & Thin & 3 & 2.6 & 5 & 4.3 & 8 & 3.5 & 0.427 \\
\hline & Normal & 27 & 23.5 & 31 & 27 & 58 & 25.2 & \\
\hline & overweight & 47 & 40.9 & 42 & 36.5 & 89 & 38.7 & \\
\hline & Obese & 23 & 20.0 & 29 & 25.2 & 52 & 22.6 & \\
\hline & Very obese & 15 & 13.0 & 8 & 7 & 23 & 10 & \\
\hline \multirow[t]{2}{*}{ Smoking } & yes & 20 & 17.4 & 23 & 20 & 43 & 18.7 & 0.61 \\
\hline & no & 95 & 82.6 & 92 & 80 & 187 & 81.3 & \\
\hline \multirow[t]{2}{*}{ Retinopathy } & yes & 66 & 57.4 & 25 & 21.7 & 91 & 39.6 & $<0.001$ \\
\hline & no & 49 & 42.6 & 90 & 78.3 & 139 & 60.4 & \\
\hline \multirow[t]{2}{*}{ microalbuminuria } & yes & 79 & 68.7 & 27 & 23.5 & 106 & 46.1 & $<0.001$ \\
\hline & no & 36 & 31.3 & 88 & 76.5 & 124 & 53.9 & \\
\hline \multirow[t]{4}{*}{ Diabetes duration (y) } & $<2$ & 6 & 5.2 & 12 & 10.4 & 18 & 7.8 & 0.456 \\
\hline & $3-5$ & 16 & 13.9 & 16 & 13.9 & 32 & 13.9 & \\
\hline & $6-10$ & 30 & 26.1 & 32 & 27.8 & 62 & 27 & \\
\hline & $>10$ & 63 & 54.8 & 55 & 47.8 & 118 & 51.3 & \\
\hline $\mathrm{SBP}(\mathrm{mmHg})$ & - & $136.78 \pm 16.57$ & & $132.52 \pm 16.27$ & & $134.65 \pm 16.52$ & & 0.05 \\
\hline $\mathrm{DBP}(\mathrm{mmHg})$ & - & $80.57 \pm 10.45$ & & $79.87 \pm 10.85$ & & $80.22 \pm 10.63$ & & 0.621 \\
\hline $\mathrm{FBS}(\mathrm{mg} / \mathrm{dl})$ & - & $206.59 \pm 76.60$ & & $176.34 \pm 63.14$ & & $191.47 \pm 71.66$ & & $0.001^{*}$ \\
\hline $\mathrm{HbA1c}(\%)$ & - & $8.42 \pm 1.09$ & & $7.45 \pm 1.14$ & & $7.94 \pm 1.21$ & & $<0.001$ \\
\hline Creatinine (mg/dl) & - & $0.99 \pm 0.16$ & & $0.89 \pm 0.15$ & & $0.94 \pm 0.16$ & & $<0.001$ \\
\hline Cholesterol (mg/dl) & - & $178.70 \pm 46.85$ & & $155.87 \pm 40.62$ & & $167.28 \pm 45.22$ & & $<0.001$ \\
\hline $\mathrm{LDL}(\mathrm{mg} / \mathrm{dl})$ & - & $102.09 \pm 35.87$ & & $88.17 \pm 34.06$ & & $95.3 \pm 35.59$ & & $0.003^{*}$ \\
\hline $\mathrm{HDL}(\mathrm{mg} / \mathrm{dl})$ & - & $39.72 \pm 7.56$ & & $39.71 \pm 7.5$ & & $39.72 \pm 7.5$ & & 0.05 \\
\hline Triglyceride (mg/dl) & - & $203.23 \pm 84.63$ & & $170.27 \pm 63.97$ & & $186.75 \pm 86.65$ & & 0.621 \\
\hline
\end{tabular}


was significantly higher in the DPN group compared to the control group.

Table 2 represents the results of comparing the SUA between the two groups. The mean SUA in the DPN group was significantly higher than the control group $(6.72 \pm 1.75 \mathrm{mg} / \mathrm{dL}$ vs. $4.57 \pm 1.49 \mathrm{mg} / \mathrm{dL}) \quad(P<0.001)$.
Moreover, the level of SUA was significantly higher in the DPN group (11.3\% vs. 1.7\%).

The results of logistic regression for the relationship between SUA and diabetic peripheral polyneuropathy adjusted for other variables in the model are reported in Table 3. It revealed that SUA was significantly

Table 2 Comparing Serum uric acid levels between the DPN group and control group

\begin{tabular}{|c|c|c|c|c|c|c|}
\hline \multirow[t]{2}{*}{ Variable } & \multirow[t]{2}{*}{ LEVEL } & \multicolumn{2}{|l|}{ DPN } & \multicolumn{2}{|l|}{ Control } & \multirow[t]{2}{*}{$P$-value } \\
\hline & & $\mathrm{n}$ & $\%$ & $\mathrm{n}$ & $\%$ & \\
\hline \multirow{4}{*}{$\begin{array}{l}\text { Serum uric acid level } \\
(\mathrm{mg} / \mathrm{dl})\end{array}$} & $\leq 5$ & 22 & 19.1 & 88 & 76.5 & \multirow[t]{4}{*}{$<0.001$} \\
\hline & $5.1-7$ & 51 & 44.3 & 19 & 16.5 & \\
\hline & $7.1-9$ & 29 & 25.2 & 6 & 5.2 & \\
\hline & $>9$ & 13 & 11.3 & 2 & 1.7 & \\
\hline $\begin{array}{l}\text { Serum uric acid } \\
(\text { Mean } \pm \text { SD) }(\mathrm{mg} / \mathrm{dl})\end{array}$ & - & $6.72 \pm 1.75$ & & $4.57 \pm 1.49$ & & $<0.001$ \\
\hline
\end{tabular}

Table 3 Results of logistic regression in relation between DPN and Serum uric acid after adjusting for other factors

\begin{tabular}{|c|c|c|c|c|c|c|c|}
\hline \multirow[t]{2}{*}{ Model } & \multirow[t]{2}{*}{ Variable } & \multirow[t]{2}{*}{ B } & \multirow[t]{2}{*}{ S.E } & \multirow[t]{2}{*}{$P$-value } & \multirow[t]{2}{*}{ OR } & \multicolumn{2}{|c|}{ 95\% C.I. for OR } \\
\hline & & & & & & Lower & Upper \\
\hline \multirow[t]{19}{*}{ Unadjusted } & Serum uric acid & 0.821 & 0.147 & 0.000 & 2.272 & 1.702 & 3.033 \\
\hline & Age & 0.001 & 0.028 & 0.977 & 1.001 & 0.948 & 1.056 \\
\hline & Gender & -0.790 & 0.673 & 0.240 & 0.454 & 0.121 & 1.697 \\
\hline & BMl & -0.070 & 0.049 & 0.159 & 0.933 & 0.846 & 1.028 \\
\hline & SBP & 0.051 & 0.019 & 0.006 & 1.052 & 1.014 & 1.091 \\
\hline & DBP & -0.057 & 0.028 & 0.040 & 0.945 & 0.895 & 0.997 \\
\hline & Smoking & -0.749 & 0.727 & 0.303 & 0.473 & 0.114 & 1.967 \\
\hline & Retinopathy & 1.119 & 0.434 & 0.010 & 3.062 & 1.309 & 7.164 \\
\hline & Diabetes duration (y) & -0.005 & 0.032 & 0.880 & 0.995 & 0.934 & 1.060 \\
\hline & Hypertension history & -1.416 & 0.513 & 0.006 & 0.243 & 0.089 & 0.664 \\
\hline & Cardiovascular history & 0.683 & 0.492 & 0.165 & 1.980 & 0.755 & 5.191 \\
\hline & $\mathrm{FBS}(\mathrm{mg} / \mathrm{dl})$ & 0.003 & 0.003 & 0.435 & 1.003 & 0.996 & 1.009 \\
\hline & $\mathrm{HbA1c}$ & 0.363 & 0.209 & 0.082 & 1.438 & 0.955 & 2.165 \\
\hline & Creatinine (mg/dl) & -0.117 & 1.763 & 0.947 & 0.889 & 0.028 & 28.157 \\
\hline & Microalbuminuria & 1.438 & 0.550 & 0.009 & 4.213 & 1.432 & 12.390 \\
\hline & Cholesterol (mg/dl) & 0.012 & 0.018 & 0.515 & 1.012 & 0.977 & 1.048 \\
\hline & LDL (mg/dl) & -0.013 & 0.019 & 0.481 & 0.987 & 0.951 & 1.024 \\
\hline & HDL (mg/dl) & -0.012 & 0.035 & 0.725 & 0.988 & 0.923 & 1.058 \\
\hline & Triglyceride (mg/dl) & -0.003 & 0.004 & 0.395 & 0.997 & 0.990 & 1.004 \\
\hline \multirow[t]{7}{*}{ Adjusted } & Serum uric acid (mg/dl) & 0.768 & 0.130 & $0.000^{*}$ & 2.155 & 1.671 & 2.781 \\
\hline & Gender (male vs. female) & -1.059 & .463 & $0.022^{*}$ & 0.347 & 0.140 & 0.859 \\
\hline & SBP & 0.049 & 0.018 & $0.005^{*}$ & 1.051 & 1.015 & 1.088 \\
\hline & Retinopathy & 1.190 & 0.404 & $0.003^{*}$ & 3.288 & 1.491 & 7.252 \\
\hline & Hypertension history & -1.457 & 0.464 & $0.002^{*}$ & 0.233 & 0.094 & 0.578 \\
\hline & $\mathrm{HbA} 1 \mathrm{c}$ & 0.341 & 0.177 & 0.054 & 1.406 & .994 & 1.989 \\
\hline & Microalbuminuria & 1.491 & 0.410 & $0.001^{*}$ & 4.440 & 1.988 & 9.920 \\
\hline
\end{tabular}


associated with neuropathy in both adjusted $(P<0.001$, $\mathrm{OR}=2.2)$ and the non-adjusted models $(P<0.001$, $\mathrm{OR}=2.3$ ). With increasing the SUA, the probabilities of developing neuropathy increased by 2.2 times $(\mathrm{OR}=2.2)$. Moreover, the results indicated that male patients were less likely to develop polyneuropathy compared to females $(P=0.022$, $\mathrm{OR}=0.347)$ so that women were 2.9 times at risk of polyneuropathy. Systolic blood pressure $(P=0.005$, OR $=1.1)$ and Retinopathy $(P=0.003, \mathrm{OR}=3.29)$ increased the risk of polyneuropathy. A history of hypertension reduced the risk of developing polyneuropathy $(P=0.002$, $\mathrm{OR}=0.233)$. The microalbuminuria incremented the risk of developing polyneuropathy by 4.4 times $(P<0.001, \mathrm{OR}=4.44)$.
Table 4 presents the results of comparing SUA levels in terms of patients' demographic per groups. In the DPN group, SUA level was affected by an older age $(P<0.003)$, male gender $(P<0.009)$, high BMI (very obese) $(P<0.008)$, retinopathy $(P<0.004)$ and microalbuminuria, hypertension history $(P<0.005)$, and heart disease. Furthermore, a significant positive association was found between SUA with the quantitative variables in the DPN group and age $(r=0.282, P=0.002)$, BMI $(\mathrm{r}=0.194, P=0.38)$, diabetes duration $(\mathrm{r}=0.091, P=0.334)$, diastolic blood pressure $(r=0.189, P=0.043)$ and creatinine $(r=0.206, P=0.027)$.

Regarding the significant relationship between SUA and DPN, the ROC curve was used to predict SUA for polyneuropathy in a person with type 2 diabetes (Fig. 1). The area under the level of SUA for predicting

Table 4 Association between patients 'characteristics and uric acid in DPN group and control group

\begin{tabular}{|c|c|c|c|c|c|c|c|}
\hline \multirow[t]{2}{*}{ Variable } & \multirow[t]{2}{*}{ level } & \multicolumn{2}{|c|}{ Control $^{\mathrm{a}}$} & \multicolumn{2}{|l|}{$\mathrm{DPN}^{\mathrm{b}}$} & \multirow[t]{2}{*}{$P$-value ${ }^{a}$} & \multirow[t]{2}{*}{$P$-value ${ }^{b}$} \\
\hline & & Mean & SD & Mean & SD & & \\
\hline \multirow[t]{3}{*}{ Age (y) } & $<50$ & 4.51 & 1.31 & 6.08 & 1.43 & 0.312 & $0.003^{*}$ \\
\hline & $51-60$ & 4.37 & 1.32 & 6.40 & 1.67 & & \\
\hline & $>60$ & 4.85 & 1.75 & 7.42 & 1.79 & & \\
\hline \multirow[t]{2}{*}{ Gender } & Female & 4.20 & 1.10 & 6.42 & 1.55 & $<0.001$ & $0.009^{*}$ \\
\hline & Male & 5.50 & 1.90 & 7.34 & 2.00 & & \\
\hline \multirow[t]{5}{*}{ BMl } & Thin & 5.26 & 1.86 & 6.50 & 2.43 & 0.112 & $0.008^{*}$ \\
\hline & Normal & 4.06 & 0.90 & 6.96 & 200 & & \\
\hline & overweight & 4.67 & 1.66 & 6.09 & 1.59 & & \\
\hline & Obese & 4.64 & 1.63 & 7.01 & 1.46 & & \\
\hline & Very obese & 5.40 & 1.29 & 7.83 & 1.46 & & \\
\hline Smoking & yes & 5.33 & 2.09 & 7.00 & 2.16 & $0.006^{*}$ & 0.438 \\
\hline Retinopathy & yes & 4.83 & 1.95 & 6.84 & 1.72 & 0.332 & $0.004^{*}$ \\
\hline \multirow[t]{4}{*}{ Diabetes duration (y) } & $<2$ & 4.14 & 1.21 & 6.85 & 2.42 & 0.176 & 0.919 \\
\hline & $3-5$ & 4.26 & 1.07 & 6.60 & 2.21 & & \\
\hline & $6-10$ & 4.35 & 1.36 & 6.56 & 1.85 & & \\
\hline & $>10$ & 4.89 & 1.68 & 6.81 & 1.54 & & \\
\hline Hypertension history & yes & 4.75 & 1.61 & 7.05 & 1.56 & 0.061 & $0.005^{*}$ \\
\hline Cardiovascular history & yes & 4.51 & 1.44 & 6.49 & 1.85 & 0.832 & 0.350 \\
\hline \multirow[t]{2}{*}{ Microalbuminuria } & yes & 4.85 & 1.88 & 6.86 & 1.79 & 0.279 & 0.211 \\
\hline & & $\mathbf{R}$ & $p$-value & $\mathbf{R}$ & $p$-value & & \\
\hline SBP & - & 0.126 & 0.178 & 0.160 & 0.087 & & \\
\hline $\mathrm{DBP}$ & - & 0.189 & $0.043^{*}$ & 0.161 & 0.085 & & \\
\hline FBS (mg/dl) & - & -0.064 & 0.498 & 0.019 & 0.840 & & \\
\hline $\mathrm{HbA} 1 \mathrm{c}$ & - & 0.138 & 0.141 & 0.119 & 0.207 & & \\
\hline Creatinine (mg/dl) & - & 0.206 & $0.027^{*}$ & 0.251 & $0.007^{*}$ & & \\
\hline Cholesterol (mg/dl) & - & -0.015 & 0.871 & -0.014 & 0.885 & & \\
\hline $\mathrm{LDL}(\mathrm{mg} / \mathrm{dl})$ & - & -0.029 & 0.757 & -0.019 & 0.840 & & \\
\hline $\mathrm{HDL}(\mathrm{mg} / \mathrm{dl})$ & - & -0.150 & 0.109 & -0.126 & 0.178 & & \\
\hline Triglyceride (mg/dl) & - & 0.082 & 0.381 & 0.044 & 0.643 & & \\
\hline
\end{tabular}




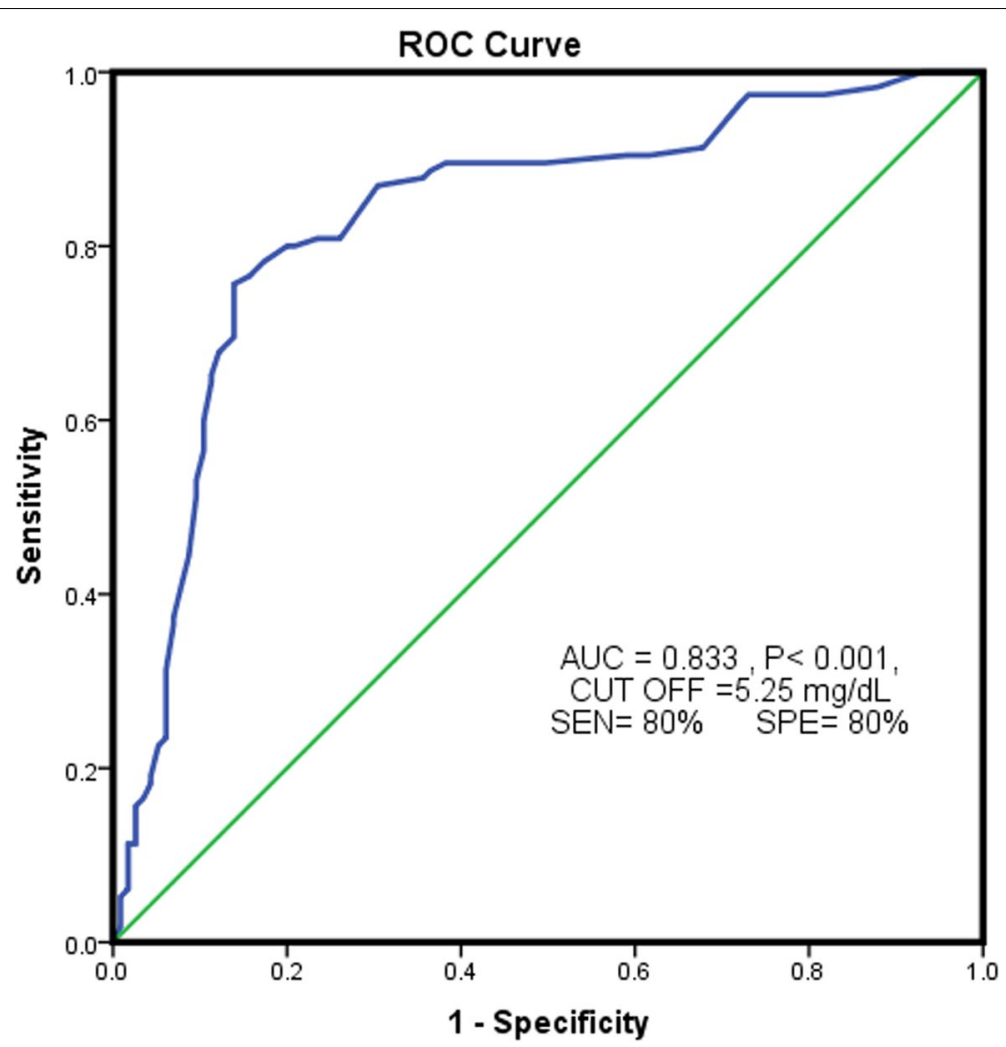

Fig. 1 ROC curve to predict uric acid level for diabetic polyneuropathy

diabetic neuropathy was statistically significant $(P<0.001$, $\mathrm{AUC}=0.833$ ). Considering sensitivity and specificity values, the best cut-off point for SUA was $5.25 \mathrm{mg} / \mathrm{dL}$, for which sensitivity and specificity were $80 \%$. The people with type 2 diabetes with SUA levels $>5.25 \mathrm{mg} / \mathrm{dL}$ were at a higher risk of polyneuropathy.

\section{Discussion}

DPN is one of the most common chronic microvascular complications in T2DM. The high SUA level is associated with an increase in DPN. Moreover, reduced mobility and sensation and increased disability can be caused by DPN. Also, recent reports declare that younger adults with a high level of SUA are at a higher risk of developing type 2 diabetes independent of other well-known risk factors such as BMI, physical activity level, age, hypertension, alcohol consumption, smoking, levels of glucose, creatinine, triglycerides, and cholesterol [20,21].

In this study, we aimed to investigate the relationship between SUA levels and diabetic peripheral polyneuropathy in patients with type 2 diabetes referring to RAZI Clinic in Rasht during 2019-2020. Our results revealed that the mean SUA in the DPN group was significantly higher than the control group $(6.72 \mathrm{mg} / \mathrm{dL}$ vs. $4.57 \mathrm{mg} /$
dL). Similar results were reported in studies by Papanas et al. [22] and Xiaopu Lin [19].

Moreover, in the present study, the high level of SUA was significantly more in the DPN group (11.3\% vs. $1.7 \%)$. Regarding the SUA classification in the study by Xiaopu Lin et al. (20), its frequency percentage in DPN patients was higher than the control group (level of $>9: 11.3 \%$ vs. 1.7; the level of 7.1- 9: $25.2 \%$ vs. $5.2 \%$; the level of 7-5.1: $44.3 \%$ vs. $16.5 \%)$. Also, according to the results obtained from the ROC curve in the present study, the patients with high levels of SUA (>5.25 mg /dL) were at a higher risk of developing polyneuropathy. In the study of Xiaopu Lin et al. [19], SUA levels $>7.8 \mathrm{mg} / \mathrm{dL}$ were associated with an increased incidence of polyneuropathy. Wisit Kaewput et al., (2002) found that an SUA level $\geq 7.3 \mathrm{mg} /$ $\mathrm{dL}$ was found to be associated with an increased peripheral neuropathy compared with an SUA level $<4.4 \mathrm{mg} / \mathrm{Dl}$ (OR,1.54) [14].

SUA was significantly associated with neuropathy based on the results of logistic regression for the relationship between SUA and diabetic peripheral polyneuropathy adjusted for other variables in the model. With increasing the SUA, the odds of developing neuropathy increased by 2.2 times $(\mathrm{OR}=2.2)$. Considering our results, it should be noted that the studied population 
included high-risk individuals, which could justify the results. In this regard, the results of previous studies pointed to the high levels of SUA and its association with type 2 diabetes [20].

Smith et al. revealed that Metabolic Syndrome features increased in 219 individuals with idiopathic neuropathy in comparison with controls without neuropathy [23].

According to previous studies from 2011 to 2014, increased SUA levels were associated with the risk of diabetic polyneuropathy. They may also be affected by diabetic polyneuropathy so that hyperuricemia increases the chance of developing diabetic peripheral polyneuropathy by about 2.83 [16]. These studies revealed that SUA was significantly higher in diabetic polyneuropathy [22, 24]. Regarding the conflict results, more studies have recently been conducted to investigate the relationship between SUA and DPN. Lin et al., (2017) studied 200 people with type 2 diabetes and found that systolic and SUA were different between the two groups with and without DPN [19]. However, a study by Laura Gaita et al., (2019), on 133 individuals with type 2 diabetes showed that there was no association between hyperuricemia and diabetic polyneuropathy [25]. In other results of the present study, gender $(\mathrm{OR}=0.347)$, systolic blood pressure $(\mathrm{OR}=1.1)$, retinopathy $(\mathrm{OR}=3.29)$, and microalbuminuria $(\mathrm{OR}=4.44)$ were identified as risk factors for polyneuropathy. Male patients were less likely to develop polyneuropathy compared to females $(\mathrm{OR}=0.347)$ so that women were 2.9 times at risk of polyneuropathy. Abraham et al., (2017) examined the clinical records, neurological and electrophysiological examinations, and laboratory findings of 115 DPN patients and comparing them with 23 controls and 38 people with type 2 diabetes without DPN. They found a positive correlation between SUA levels, male gender, and hypertension [26].

In the present study, retinopathy was observed in $57.2 \%$ of patients with DPN. Moreover, the chance of developing polyneuropathy in patients with retinopathy was about 3.3 times higher than in the control group. In the study conducted by Papanas et al., [22], the frequency percent of retinopathy was $62.5 \%$ in DPN patients and $48.5 \%$ in the control group. However, no significant difference was reported between the two groups. Hou et al., (2020) indicated that the higher levels of SUA (Q3 and Q4) were associated with greater risk for diabetic retinopathy, compared with the lower level (Q1) (odds ratio [OR]: 3.056, 95\% confidence interval [CI]: 1.506-6.198; OR: 3.417, 95\% CI: 1.635-7.139, respectively) [27].

In the present study, the frequency of microalbuminuria in DPN was $68.7 \%$ and the chance of developing microalbuminuria was 4.4 times higher in patients than in the control group. Papanas et al., [22] found no statistically significant difference between the two study groups in terms of microalbuminuria. Hou et al., (2020) revealed that the higher levels of SUA (Q2, Q3, and Q4) were associated with greater risk for albuminuria (OR: 2.418, 95\% CI: 1.059-5.522; OR: 7.233, 95\% CI: 3.145-16.635; and OR: $8.911,95 \%$ CI: $3.755-21.147$, respectively) [27]. In the present study, the mean systolic blood pressure in patients with DPN was higher than in the control group. Similar results were reported in the study by Lin et al. [19]. The current study encountered some limitations. First, since this was a single-center study, the generalizability of the results to other regions may require further investigation. Second, some patients withdrew from the study.

\section{Conclusion}

In the present study, the mean serum level of SUA in a person with type 2 diabetes with peripheral polyneuropathy was significantly higher than the control group. With increasing one unit of SUA, the chance of developing peripheral polyneuropathy in patients increased about 2.2 times. The higher level of SUA level above $5.25 \mathrm{mg}$ / dL exposed the patient to peripheral polyneuropathy. Further prospective cohort studies are required to evaluate the effect of SUA levels on diabetic peripheral polyneuropathy and disease progression.

\section{Abbreviations}

BMI: Body mass index; Cl: Confidence interval; DPN: Diabetic Peripheral Neuropathy; NDS: Neuropathy Disability Score; DNS: Diabetic neuropathy symptom score; EMG: Electromyography; NCV: Nerve conduction velocity; SUA: Serum uric acid;T2DM: Type 2 diabetes mellitus; OR: Odds ratio.

\section{Acknowledgements}

Thanks to guidance and advice from "Razi Clinical Research Development Unit, Guilan University of Medical Sciences".

\section{Authors' contributions}

HSF and MY: Conceived and designed the experiments: SSM and ZSH. Performed the experiments: ZSH and ASA; Analyzed the data: SSM and MY; Contributed reagents/materials /analysis tools: ASA and SSM; Contributed to the writing of the manuscript: RR and MH. The author(s) read and approved the final manuscript.

\section{Funding \\ Self-funding.}

\section{Availability of data and materials}

The datasets used and/or analyzed during the current study are available from the corresponding author on reasonable request.

\section{Declarations}

Ethics approval and consent to participate

This study was also confirmed and permitted by the Ethics Committee of Guilan University of Medical Science" IR.GUMS.REC.1399.171" and was conducted in agreement with the Declaration of Helsinki. Informed consent was obtained from all individual participants.

Consent for publication

Not applicable. 


\section{Competing interests}

The authors report no conflicts of interest in this work.

\section{Author details}

${ }^{1}$ Department of Internal Medicine, School of Medicine, Razi Hospital, Guilan University of Medical Sciences, Rasht, Iran. ${ }^{2}$ Razi Clinical Research Development Unit, Guilan University of Medical Sciences, Rasht, Iran.

Received: 2 April 2021 Accepted: 3 February 2022

Published online: 12 February 2022

\section{References}

1. Peterson SB, Hart GW. New insights: A role for O-GlcNAcylation in diabetic complications. Crit Rev Biochem Mol Biol. 2016;51:150-61.

2. Atlas D. International diabetes federation. IDF Diabetes Atlas. 7th ed. Brussels: International Diabetes Federation; 2015.

3. Khan MAB, Hashim MJ, King JK, Govender RD, Mustafa H, Al Kaabi J. Epidemiology of Type 2 Diabetes - Global Burden of Disease and Forecasted Trends. J Epidemiol Glob Health. 2020;10:107-11.

4. Mehravaran $\mathrm{H}$, Makvandi M, Zade AS, Neisi N, Kiani $\mathrm{H}$, Radmehr $\mathrm{H}$, et al. Association of human cytomegalovirus with Hodgkin's disease and nonHodgkin's lymphomas. Asian Pac J Cancer Prev. 2017:18:593.

5. Association AD. Diagnosis and classification of diabetes mellitus. Diabetes Care. 2009;32:S62-7.

6. Veves A, Caselli A. Micro- and Macrovascular Disease in Diabetic Neuropathy. In: Veves A, Malik RA, editors. Diabetic Neuropathy. Clinical Diabetes. Humana Press; 2007. https://doi.org/10.1007/978-1-59745-311-0_15.

7. Yang Z, Zhang Y, Chen R, Huang Y, Ji L, Sun F, Hong T, Zhan S. Simple tests to screen for diabetic peripheral neuropathy. Cochrane Database Syst Rev. 2018;2018(7):CD010975. https://doi.org/10.1002/14651858.CD010 975.pub2.

8. Callaghan BC, Cheng HT, Stables CL, Smith AL, Feldman EL. Diabetic neuropathy: clinical manifestations and current treatments. Lancet Neurol. 2012;11:521-34

9. Kazamel M, Dyck PJ. Sensory manifestations of diabetic neuropathies: anatomical and clinical correlations. Prosthet Orthot Int. 2015;39:7-16.

10 Amour AA, Chamba N, Kayandabila J, Lyaruu IA, Marieke D, Shao ER, et al. Prevalence, patterns, and factors associated with peripheral neuropathies among diabetic patients at tertiary Hospital in the Kilimanjaro Region: descriptive cross-sectional study from north-eastern Tanzania. Int J Endocrinol. 2019;2019:5404781

11. Yang T, Chu C-H, Bai C-H, You S-L, Chou Y-C, Chou W-Y, et al. Uric acid level as a risk marker for metabolic syndrome: a Chinese cohort study. Atherosclerosis. 2012;220:525-31.

12. Krishnan E, Akhras K, Sharma H, Marynchenko M, Wu E, Tawk R, et al. Relative and attributable diabetes risk associated with hyperuricemia in US veterans with gout. Int J Med. 2013;106:721-9.

13. Choi YJ, Yoon Y, Lee KY, Hien TT, Kang KW, Kim KC, et al. Uric acid induces endothelial dysfunction by vascular insulin resistance associated with the impairment of nitric oxide synthesis. FASEB J. 2014;28:3197-204.

14. Kaewput W, Thongprayoon $C$, Rangsin $R$, Jindarat $S$, Narindrarangkura $P$ Bathini T, et al. The association between serum uric acid and peripheral neuropathy in patients with type 2 diabetes mellitus: a multicenter nationwide crosssectional study. Korean J Fam Med. 2020;41:189.

15. Ito H, Abe M, Mifune M, Oshikiri K, Antoku S, Takeuchi Y, et al. Hyperuricemia is independently associated with coronary heart disease and renal dysfunction in patients with type 2 diabetes mellitus. Plos One. 2011;6:e27817.

16. Yu S, Chen Y, Hou X, Xu D, Che K, Li C, et al. Serum uric acid levels and diabetic peripheral neuropathy in type 2 diabetes: a systematic review and meta-analysis. Mol Neurobiol. 2016;53:1045-51.

17. Johnson RJ, Nakagawa T, Sanchez-Lozada LG, Shafiu M, Sundaram S, Le M et al. Sugar, uric acid, and the etiology of diabetes and obesity. Diabetes. 2013:62:3307-15.

18. Niu S-W, Chang K-T, Ta A, Chang Y-H, Kuo IC, Hung C-C, et al. Decreased incidence of diabetes in patients with gout using benzbromarone. Rheumatology. 2018;57:1574-82.
19. Lin X Xu L, Zhao D, Luo Z, Pan S Correlation between serum uric acid and diabetic peripheral neuropathy in T2DM patients. J Neurol Sci. 2018:385:78-82.

20. Bhole V, Choi JW, Kim SW, de Vera M, Choi H. Serum uric acid levels and the risk of type 2 diabetes: a prospective study. Am J Med. 2010;123:957-61.

21. Ko SH, Cha BY. Diabetic peripheral neuropathy in type 2 diabetes mellitus in Korea. Diabetes Metab J. 2012;36:6-12.

22. Papanas N, Katsiki N, Papatheodorou K, Demetriou M, Papazoglou D, Gioka T, et al. Peripheral neuropathy is associated with increased serum levels of uric acid in type 2 diabetes mellitus. Angiology. 2011;62:291-5.

23. Smith AG, Rose K, Singleton JR. Idiopathic neuropathy patients are at high risk for metabolic syndrome. J Neurol Sci. 2008;273:25-8.

24. Kiani J, Habibi Z, Tajziehchi A, Moghimbeigi A, Dehghan A, Azizkhani $H$. Association between serum uric acid level and diabetic peripheral neuropathy (A case control study). Caspian J Intern Med. 2014;5:17.

25. Gaita L, Timar R, Lupascu N, Roman D, Albai A, Potre O, et al. The impact of hyperuricemia on cardiometabolic risk factors in patients with diabetes mellitus: a cross-sectional study. Diabetes Metab Syndr Obes. 2019;12:2003.

26. Abraham A, Breiner A, Barnett C, Katzberg HD, Lovblom LE, Perkins BA et al. Uric acid levels correlate with the severity of diabetic sensorimotor polyneuropathy. J Neurol Sci. 2017;379:94-8.

27. Hou L, Shi Y, Wang S, Chen Q, Li Q, Zhao M, et al. Associations of serum uric acid level with diabetic retinopathy and albuminuria in patients with type 2 diabetes mellitus. J Int Med Res. 2020;48:0300060520963980.

\section{Publisher's Note}

Springer Nature remains neutral with regard to jurisdictional claims in published maps and institutional affiliations.

Ready to submit your research? Choose BMC and benefit from

- fast, convenient online submission

- thorough peer review by experienced researchers in your field

- rapid publication on acceptance

- support for research data, including large and complex data types

- gold Open Access which fosters wider collaboration and increased citations

- maximum visibility for your research: over 100M website views per year

At $\mathrm{BMC}$, research is always in progress.

Learn more biomedcentral.com/submissions 